\title{
Protective efficacy of recombinant canine adenovirus type-2 expressing TgROP18 (CAV-2-ROP18) against acute and chronic Toxoplasma gondii infection in mice
}

\author{
Xiu-Zhen Li ${ }^{1,2+}{ }^{1}$, Xiao-Hu Wang ${ }^{3+}$, Li-Jun Xia ${ }^{1,2}$, Ya-Biao Weng ${ }^{1}$, Jorge A Hernandez ${ }^{4}$, Li-Qing Tu ${ }^{1,2}$, Lu-Tao Li ${ }^{1,2}$,
} Shou-Jun Li, $\mathrm{i}^{1,2}$ and Zi-Guo Yuan ${ }^{1,2^{*}}$

\begin{abstract}
Background: The use of recombinant viral vectors expressing T. gondii antigens is a safe and efficient approach to induce immune responses against the parasite, as well as a valuable tool for vaccine development. We have previously prolonged the survival time of mice challenged with the $\mathrm{RH}$ strain of $\mathrm{T}$. gondii by immunizing the mice with a eukaryotic vector expressing the protein ROP18 of T. gondii. We are now looking for ways to improve this vaccination strategy and enhance protection.

Methods: In this study, we constructed and characterized a novel recombinant canine adenovirus type 2 expressing ROP18 (CAV-2-ROP18) of T. gondii by cytopathic effect (CPE) and indirect immunofluorescence assay (IFA) following transfection into MDCK cells. Intramuscular immunization of Kunming mice with CAV-2-ROP18 was carried out to evaluate humoral and cellular immune responses.

Results: The vaccination of experimental mice with CAV-2-ROP18 elicited antibody production against ROP18, including high levels of a mixed IgG1/lgG2a and significant production of IFN- $\gamma$ or IL-2, and displayed a significant bias towards a helper T cell type 1 (Th1) profile. Furthermore, the presence of T. gondii-specific IFN- $\gamma$-production and TNF-a-production $T$ cells was elicited in both $C^{4+}$ and $C D^{8+} T$ cell compartments. Significantly higher survival rates (40\%) occurred in the experimental group, and a reduction in brain cyst burden was detected in vaccinated mice.
\end{abstract}

Conclusion: These results demonstrate the potential use of a CAV vector harboring the ROP18 gene in the development of a vaccine against acute and chronic toxoplasmosis.

Keywords: Toxoplasma gondi, Recombinant virus CAV-2-ROP18, Protective immunity, Mice

\section{Background}

Toxoplasma gondii is an obligate, intracellular parasite which belongs to the phylum Apicomplexa [1]. The parasite can infect all warm-blooded mammals. In humans it is one of the major opportunistic parasites that infects immunocompromised individuals and pregnant women [2-4], causing congenital defects in newborns and

\footnotetext{
* Correspondence: ziguoyuan@scau.edu.cn

${ }^{\dagger}$ Equal contributors

${ }^{1}$ College of Veterinary Medicine, South China Agricultural University, Guangzhou, Guangdong Province 510642, PR China

${ }^{2}$ Guangdong Provincial Key Laboratory of Prevention and Control for Severe Clinical Animal Diseases, Guangzhou, Guangdong Province 510642, PR China Full list of author information is available at the end of the article
}

severe, disseminated disease in adults. Toxoplasmosis also causes considerable economic losses in livestock, especially in pigs and sheep [5]. Chemical treatments for acute and chronic toxoplasmosis are currently available, but they are not acceptable due to parasite drug-resistant and chemical residues in food [6,7]. Because of the public health and eco2nomic consequences of $T$. gondii infection in humans and animals, the development of a vaccine is needed for disease prevention.

The T. gondii ROP18 protein is a polymorphic serinethreonine kinase which is secreted in the host cell during the invasion process, and its catalytic activity is required for the acute virulence phenotype. ROP18 is considered 
one of the key virulence factors in the pathogenesis of the T. gondii infection $[8,9]$. Previous research has demonstrated that an additional ligand-binding pocket outside of the active site cleft is a key element of the ROP18 Ser/Thr protein kinase for mediating acute virulence in mice [10].

The use of recombinant viral vectors has great potential for the development of more immunogenic vaccines against protozoan parasites. Viral vectors typically elicit efficient expression of the foreign antigens they encode, which facilitate the presentation and development of specific immune responses against the recombinant antigen $[11,12]$. Here we describe the development of a recombinant canine adenovirus expressing the ROP18 gene of $T$. gondii that partially protected mice against challenge with the RH strain (genotype I) and Prugniaud (PRU) strain (genotype II) of $T$. gondii.

\section{Methods}

Mice, cell and parasites

One hundred and thirty-two specific-pathogen-free (SPF) grade, female, inbred Kunming mice, 6 to 8 weeks old, were purchased from the Sun Yat-Sen University Laboratory Animal Center. All mice were handled properly according to the Animal Ethics Procedures and Guidelines of the People's Republic of China. The study was approved by the Animal Ethics Committee of South China Agricultural University (permit SCAUAEM-2013-39). All mice were maintained under standard conventional conditions, with food and water ad libitum.

Madin-Darby canine kidney cell lines (MDCK) were cultivated and two T. gondii strains (RH and PRU) were used in our lab (see Additional file 1).

\section{The construction of pPolyll-CAV- $\triangle E 3-R O P 18$}

The construction of pPolyII-CAV- $\Delta$ E3-ROP18 (Figure 1) was performed as described in Additional file 2.

\section{Transfection of recombinant genome in MDCK cells and identification of ROP18 expression from CAV-2-ROP18}

Five micrograms of pPolyII-CAV- $\triangle \mathrm{E} 3-\mathrm{ROP} 18$ were digested with Asc I and Pme I to release the linear recombinant genome. After extraction with chloroform and precipitation with ethanol, the recombinant genome was used to transfect MDCK cells at 70-80\% confluency with Lipofectamine $2000^{\mathrm{TM}}$ (Invitrogen). The transfected MDCK cells were passaged routinely until a typical CAV-2 cytopathic effect (CPE) was observed.

For identification of the expression of ROP18 by recombinant CAV-2-ROP18, the indirect immunofluorescence assay (IFA) was done as reported in Additional file 3 [4].

\section{Vaccination procedure and challenge}

All mice were randomly assigned into one of four experimental groups (33 mice per group). Group I was intramuscularly inoculated once with $0.1 \mathrm{ml}$ CAV-2ROP18 (10 ${ }^{8.125}$ p.f.u. $\left.\mathrm{ml}^{-1}\right)$; group II received $0.1 \mathrm{ml}$ CAV-2 $\left(10^{8.25}\right.$ p.f.u. $\left.\mathrm{ml}^{-1}\right)$ intramuscularly once as a negative control; group III was inoculated intramuscularly with $0.1 \mathrm{ml} \mathrm{PBS}$ as control at weeks 0,2 and 4; and group IV was not injected with anything as a negative control. Blood was collected from the lateral saphenous vein of a hind limb of 5 mice per group one day prior to each immunization and at intervals of two weeks after inoculation.Sera were separated and stored at $-20^{\circ} \mathrm{C}$ until analyzed for specific antibodies. Pre-immune sera were used as negative controls.

Eight weeks after the immunization, 20 mice in each group were challenged intraperitoneally (i.p.) with $1 \times 10^{3}$ tachyzoites of the virulent T. gondii RH strain, and 10 other mice were inoculated intragastrically with 5 cysts of the PRU strain. All mice were observed daily for mortality. Two months after the challenge, the surviving mice were euthanized and their brains were removed. Each brain was homogenized in $2 \mathrm{ml}$ of PBS. The mean number of cysts per brain was determined by counting in three samples of $25 \mu \mathrm{l}$ aliquots of each homogenized brain under an optical microscope.

\section{Humoral response}

Levels of antigen-specific IgG, IgG1 and IgG2a immunoglobulins in serum samples were examined as previously described (see Additional file 4) [13].

CAV-2 hemagglutination inhibition (HI) antibody titers were determined by a micro method with a slight modification (see Additional file 5) [14].

\section{Lymphocyte proliferation assay}

At week 8 (post-immunization), splenocytes were harvested from each of the three immunized mice from each group, separately. Next, the spleen cells proliferative response was measured as mentioned above (for details, see Additional file 6) $[4,15,16]$.

\section{Cytokine assays}

Detection of cytokines was carried out according to the method previously described (see Additional file 7 for details) [4].

\section{Evaluation of CTL activity}

Peripheral blood mononuclear cells (PBMCs) of mice were segregated from 3 mice per group and single-cell suspensions were prepared from mice 8-weeks after the immunization, and the activity of cytotoxic $\mathrm{T}$ lymphocytes (CTL) was measured by CytoTox $96^{\circ}$ Non-Radioactive Cytotoxicity Assay Kits (Promega, USA) as previously reported (see Additional file 8) [15]. 


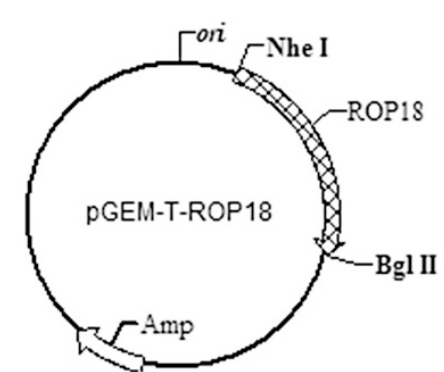

Nhe I/Bgl II

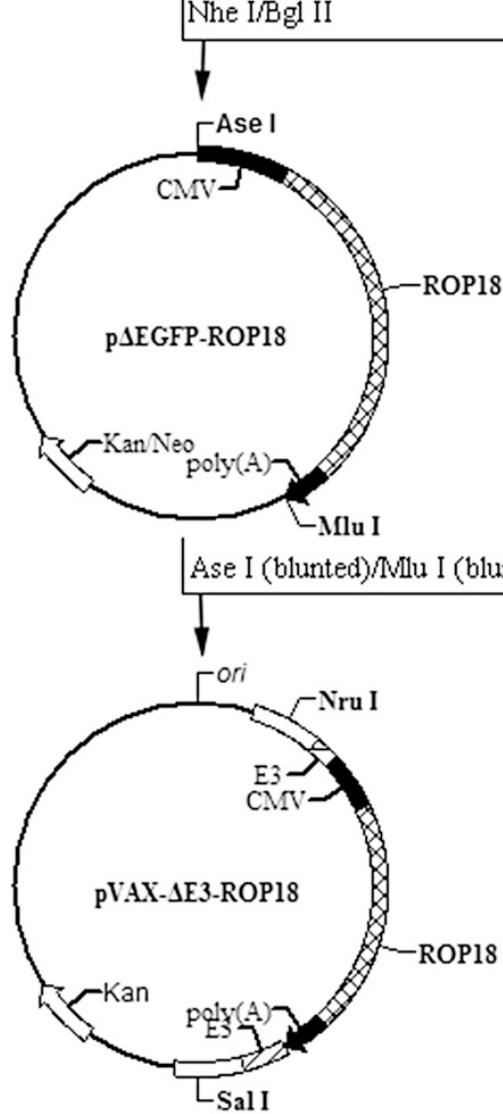

Nru I/Sal I

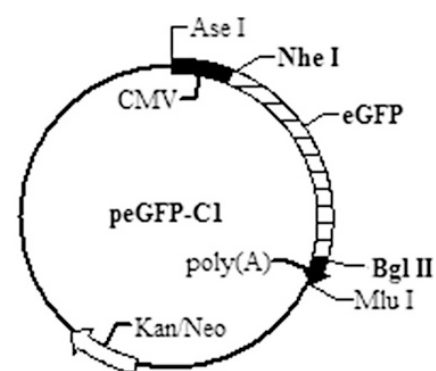

Nhe I/Bgl II

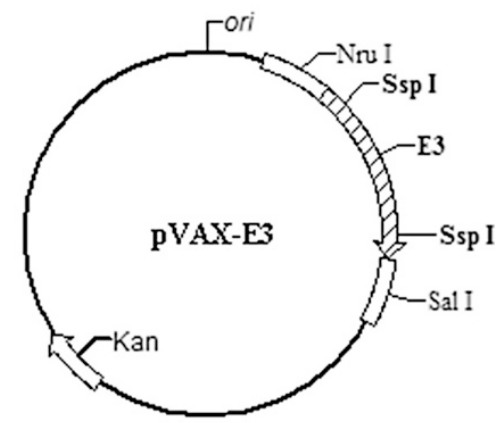

Ssp I

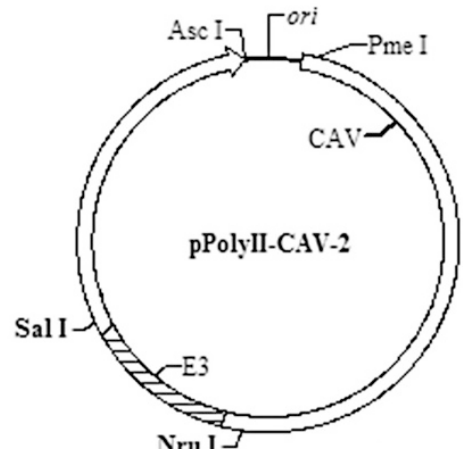

Nru I/Sal I

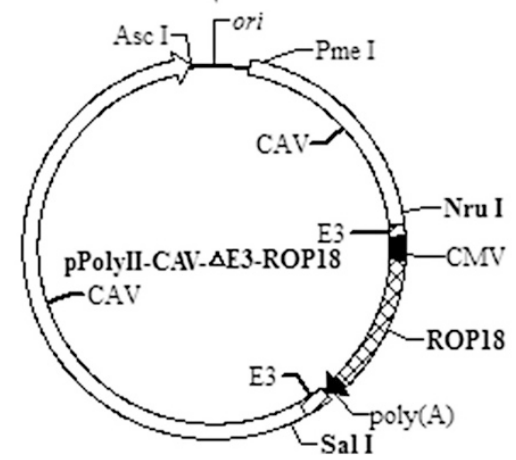

Figure 1 Schematic representation of the construction of recombinant plasmid pPolyll-CAV- $\triangle$ E3-ROP18 by in vitro ligation. E3, the E3 region of CAV-2; CMV, human cytomegalovirus (hCMV) immediate-early gene promoter; polyA, the SV40 early mRNA polyadenylation signal. Bold letters were those enzymes used in plasmid construction. 


\section{Flow cytometry analysis}

Co-expression of $\mathrm{CD} 3+$ with $\mathrm{CD} 4^{+}$and $\mathrm{CD} 8^{+}$on lymphocytes of splenocytes were determined by flow cytometry as previously mentioned (see Additional file 9) [13].

Detection of intracellular cytokines was carried out according to the method of Additional file 9 .

\section{Statistical analysis}

All data were processed and analyzed by SPSS13.0 Data Editor (SPSS Inc., Chicago, IL, USA). Mean antibody responses, lymphoproliferation, cytokine production and CTL were compared between groups by using one-way ANOVA. If data are not normally distributed, the nonparametric Kruskal-Wallis test was used in the study. Values of $P<0.05$ were considered significant.

\section{Results}

\section{Recovery and identification of CAV-2-ROP18}

Seven days after transfection of the recombinant genome pPolyII-CAV- $\triangle \mathrm{E} 3-\mathrm{ROP} 18$ into MDCK cells, typical adenovirus-like CPE (grape-cluster-like cells) was observed under an optical microscope (200x, Figure 2). The growth characteristics of the recombinant virus was similar to that of the canine adenovirus vaccine strain YCA18 (data not shown). The identification of the recombinant virus genome by restriction endonuclease digestion and PCR amplification confirmed that the ROP18 gene and its expression cassette were included in the recombinant virus (data not shown). IFA demonstrates expression of ROP18 following transduction of MDCK cells with CAV2-ROP18, whereas no fluorescence was observed in negative control MDCK cells by use of an anti-ROP18 polyclonal antiserum (Figure 3).

\section{Evaluation of humoral responses}

Using ELISA, antibody titers significantly increased in the recombinant virus CVA-2-ROP18 group at week 2, 4 and 6 after immunization, compared to CAV-2, PBS and blank control immunized group $(P<0.05)$ (Figure 4A). Subclasses of immunoglobulins specific to T. gondii were analyzed in the sera (as shown in Figure 4B). Both IgG1 and IgG2a were tested in sera of mice immunized with CAV-2-ROP18, and the ratios of IgG1 to IgG2a in the groups I - IV were 2.69, 1.02, 1.08, and 1.09, respectively. There was no significant difference in IgG1 and IgG2a levels between the groups immunized CAV-2, PBS, and nothing $(P>0.05)$. It is known that production of IgG subclasses is driven by cytokines secreted during cellular immune responses. Therefore, the presence of IgG1 and IgG2a indirectly suggests that the vaccination protocol also promoted activation of a cell-mediated response.

$\mathrm{HI}$ antibodies against CAV-2 were detected in all mice vaccinated with CAV-2 and the recombinant CAV-2ROP18 at 2 weeks post-primary immunization, reaching comparable titers throughout the test period. In addition, HI titers were up to 1:128 eight weeks after primary vaccination (Table 1 ). In mice vaccinated with PBS and those not vaccinated, specific antibodies to CAV-2 were not detected.

\section{Cellular immune response analysis}

Splenocytes from mice immunized with CAV-2-ROP18 showed a very significant proliferative response to ROP18 $(P<0.05)$, and splenocyte proliferation was $\sim 21$-fold higher than proliferation by splenocytes from groups immunized with CAV-2, PBS and negative control $(P<0.05)$. Meanwhile, splenocytes from all groups proliferated to comparable levels in response to the mitogen ConA (Table 2). Significant CTL activity was tested in mice immunized with CAV-2-ROP18 (at E:T value of 100:1; Figure 5).

For further characterization of cellular immune responses, the $\mathrm{CD}^{+} / \mathrm{CD}^{+}{ }^{+} \mathrm{T}$ cells and $\mathrm{CD}^{+} / \mathrm{CD}^{+} \mathrm{T}$ cells were shown in Figure 6.The percentage of $\mathrm{CD}^{+} / \mathrm{CD}^{+} \mathrm{T}$ cells and $\mathrm{CD}^{+} / \mathrm{CD}^{+} \mathrm{T}$ cells were significantly increased in mice immunized with CAV-2-ROP18 compared to those with CAV-2, PBS, or blank control groups. Similarly, recombinant virus immunization CAV-2-ROP18 significantly altered $\mathrm{CD}^{+}$or $\mathrm{CD}^{+}{ }^{+} \mathrm{T}$ cell profiles in terms of IFN- $\gamma$ (Figure 7) and TNF- $\alpha$ (Figure 8) expression in comparison with all controls. There was no significant difference between the three control groups $(P>0.05)$.

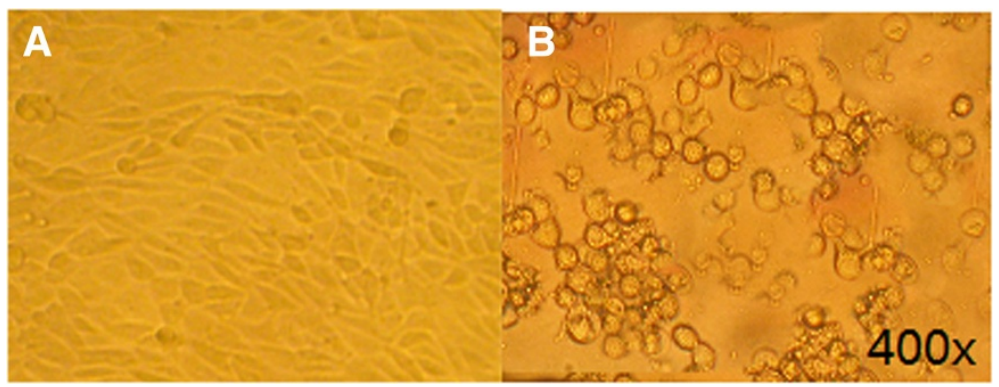

Figure 2 Cytopathic effects on MDCK cells after transfection $(\times 400)$. Normal cells $(A)$; transfected and cytopathic cells (B). 


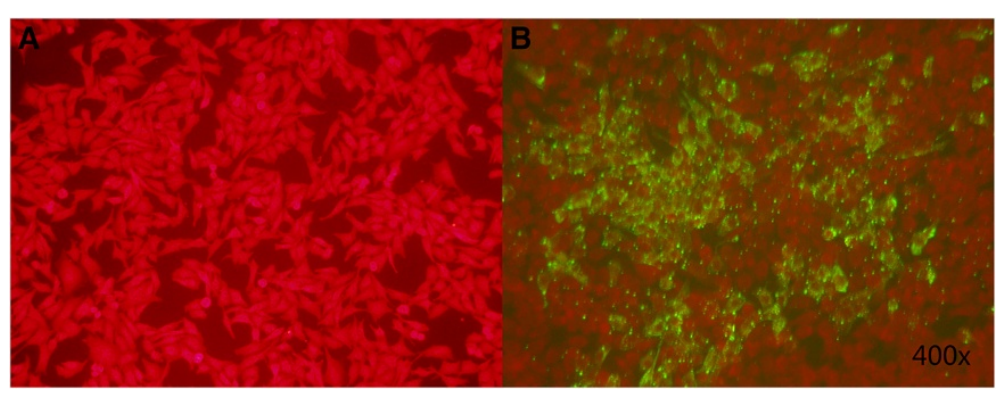

Figure 3 Expression analyses of ROP18 protein in transfected MDCK cells by IFA at $48 \mathrm{~h}$ post-transfection with a presumptive recombinant virus CAV-2-ROP18: (A) Non-transfected MDCK cells; (B) MDCK cells detected with $T$. gondii-positive serum post-transfection with a presumptive recombinant virus CAV-2-ROP18. The pictures were showed under 400× microscope.

\section{Cytokine production}

The cell-mediated immunity induced in the immunized mice was further evaluated by measuring the amount of cytokines IL-2, IL-4, IL-10 and IFN- $\gamma$. As shown in Table 2, values of IL- 2 and IFN- $\gamma$ in CAV-2-ROP18 immunization group are $431.07 \pm 28.94 \mathrm{pg} / \mathrm{ml}$ and $914.26 \pm 36.56 \mathrm{pg} / \mathrm{ml}$, which are very significantly higher than in the control groups (CAV $47.23 \pm 7.59 \mathrm{pg} / \mathrm{ml}$ and $44.28 \pm 9.37 \mathrm{pg} / \mathrm{ml}$; PBS $52.60 \pm 11.97 \mathrm{pg} / \mathrm{ml}$ and $46.13 \pm 10.27 \mathrm{pg} / \mathrm{ml}$; blank control $51.45 \pm 3.88 \mathrm{pg} / \mathrm{ml}$ and $42.98 \pm 6.76 \mathrm{pg} / \mathrm{ml})(P<$ 0.05). For IL-4, low levels of IL-4 showed a slight but significantly production from the splenocytes from mice immunized with CAV-2-ROP18, compared to three control groups $(P<0.05)$, further confirming the results of the IgG subclass. On the other hand, no statistically significant differences could be found in the amount of IL-10 between the immunized and control groups $(P>0.05)$.

\section{Protection of mice against challenge with $T$. gondii}

To examine protective immunity, 20 mice of each group were given an intraperitoneal injection of $1 \times 10^{3}$ tachyzoites of $T$. gondii RH strain at 8 weeks after vaccination. Mortality was checked daily. The percentages of survival in the different groups of mice are shown in Figure 9. Those mice immunized with only a single dose of CAV-2-ROP18 showed $40 \%$ protection until 60 days after challenge. The administration of either CAV-2 or PBS did not prevent mortality (mice died within 7 days). Also, we evaluated the immunoprotective effect by counting the number of cysts in a chronic model challenge with 5 cysts of strain PRU administration by gavage. As shown in Table 3, we observed that mice from the CAV-2-ROP18 vaccination group developed a significantly lower $(P<0.05)$ number of brain cysts $(8000 \pm$ 1414 cysts per brain) in comparison to mice from the other three control control groups (approximately 18000 cysts).

\section{Discussion}

In this study, a recombinant CAV-2 genome carrying the ROP18 expression cassette was first constructed, and the recombinant adenovirus was then generated by
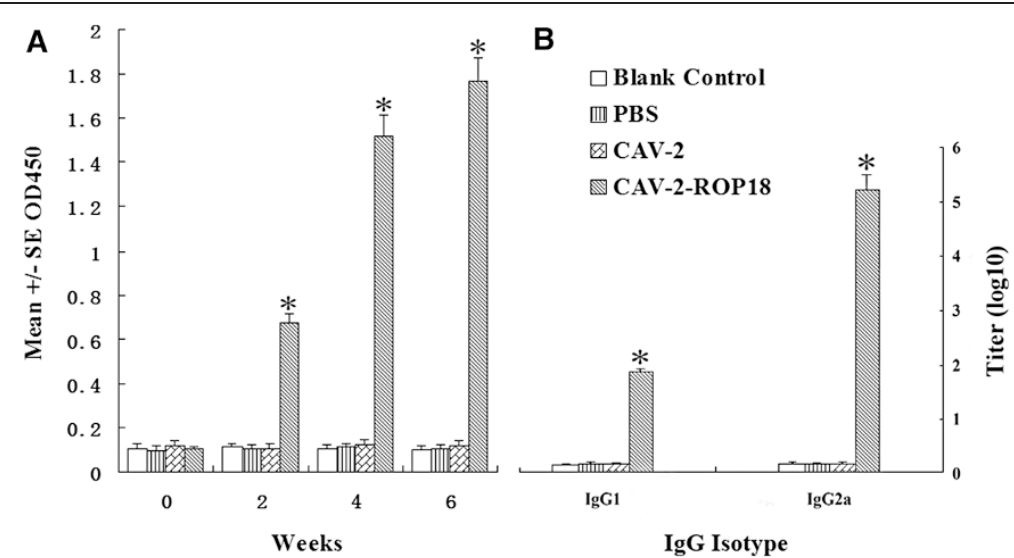

Figure 4 Detection of CAV-2-ROP18 immunization on the antibody response. Serum samples were collected at weeks $0,2,4$ and 6 post-primary immunization. (A) Determination of specific anti-ROP18 lgG antibodies in the sera of Kunming mice. (B) Determination of the specific anti-ROP18 IgG subclass profile in the sera of the immunized Kunming mice. Results are expressed as means of the $\mathrm{OD}_{490}$ value and standard deviation ( $\mathrm{n}=5$ ), and statistically significant difference $(P<0.05)$ are indicated by an asterisk $\left(^{*}\right)$. 
Table 1 CAV-2 HI antibody titers in mice immunized with PBS, CAV-2 and CAV-2-ROP18

\begin{tabular}{|c|c|c|c|c|c|c|}
\hline Group $(n=3)$ & 0 week & 2 weeks & 4 weeks & 6 weeks & 8 weeks & 10 weeks \\
\hline CAV-2-ROP18 & $<1: 2$ & 1:8-1:16 & 1:16-1:32 & $1: 64$ & $1: 128$ & 1:64-1:128 \\
\hline CAV-2 & $<1: 2$ & 1:8-1:16 & 1:16-1:32 & $1: 64$ & $1: 128$ & 1:64-1:128 \\
\hline PBS & $<1: 2$ & $<1: 2$ & $<1: 2$ & $<1: 2$ & $<1: 2$ & $<1: 2$ \\
\hline Blank Control & $<1: 2$ & $<1: 2$ & $<1: 2$ & $<1: 2$ & $<1: 2$ & $<1: 2$ \\
\hline
\end{tabular}

transfecting MDCK cells with the recombinant genome. Regarding the vaccine vectors used for ROP18 expression of T. gondii, we started our work with the replicationcompetent CAV. Besides being highly efficient for transgene expression "in vivo" and being safe for administration, adenoviral vectors also have intrinsic adjuvant properties capable of activating an innate immune response via TLR $[17,18]$ and NLR [19] receptors. Meanwhile, several different species of adenovirus have been developed by homologous recombination with insertion of foreign genes into the non-essential E3 region [20,21]. Replicationdefective adenoviruses have often been utilized as candidate vaccine vectors. However, clinical application of the best-studied human adenovirus type-5 (AdHu5) is limited by the high prevalence of preexisting immunity resulting from natural infection [22,23]. Many researchers are apprehensive about the problem of a long-acting vaccine in the animal body, because the antibodies could be produced when the animals were infected by CAV in nature. In this study we used the CAV-2 as a vector to express the ROP18 antigen, because CAV-2 is an artificial domestic strain [24], and previous exposure to CAV-2 is low [25]. In the study, titers of $\mathrm{HI}$ antibodies to CAV-2 induced by the recombinant virus CAV-2-ROP18 were similar to those induced by $\mathrm{CAV}-2$ vaccine strain, which indicates that the recombinant virus retains its ability to stimulate an effective immune response against CAV.

We also evaluated the Th1 and/or Th2 immune response in mice immunized by prime-boost strategy. The IFN- $\gamma$ secreted by Th1 cells favors the IgG2a switch, while IL-4 produced by Th2 cells regulates the IgG1 switch [26]. The development of potent Th1-type immune response is essential for the control of $T$. gondii infection $[27,28]$.
As the indicator for activated Th1 lymphocytes, the pro-inflammatory cytokines including IFN- $\gamma$ and IL-2 are also involved in the protection against the infection $[29,30]$. Our results showed that in contrast with the controls, immunization with CAV-2-ROP18 induced the production of high levels of IL-2 and IFN- $\gamma$ (as well as IgG2a), which are associated with Th1-type mediated immunity. Nevertheless, Th2-type cytokines, both IL-4 and IL-10, may partially inhibit the secretion of proinflammatory cytokines and prevent $\mathrm{CD} 4^{+} \mathrm{T}$ cell-mediated severe immunopathology during the acute and chronic stage of T. gondii invasion [31]. The production of IL-4 in early infection inhibits protective Th1 cell differentiation most likely by either direct or indirect inhibition of IFN- $\gamma$ production [32]. A slight increase in the release of IL-4 (as well as IgG1) in combination with the high levels of IL-2 and IFN- $\gamma$ suggested the activation of an appropriate $\mathrm{T}$ helper response, primarily a specific Th1-biased cellular immune response after immunization with CAV-2-ROP18. There was no difference in IL-10 production between vaccinated and control groups. The results suggested that Th1-mediated cellular immunity in the group immunized with CAV-2-ROP18 is not dependent on IL-10 production during the cellular response against toxoplasmosis.

In addition to cellular immunity, humoral immunity resulting in the production of antigen-specific IgG antibodies also seems to be important in controlling $T$. gondii invasion [33]. It has been reported that T. gondii infection could lead to B cell responses resulting in production of antibodies, which limit the spread of parasites by inhibiting the attachment of tachyzoites to host cell receptors and thus promoting intracellular killing of antibody-coated parasites by macrophages [33]. Our study

Table 2 Cytokine production by splenocytes of immunized mice after stimulation by ROP18 protein at 8-weeks post immunization*

\begin{tabular}{|c|c|c|c|c|c|c|}
\hline \multirow[t]{2}{*}{ Group $(n=3)$} & \multicolumn{4}{|c|}{ Cytokine production (pg/mL) } & \multicolumn{2}{|c|}{ Proliferation (Stimulation Index) } \\
\hline & IFN- $\gamma$ & IL-2 & IL-4 & IL-10 & ROP18 & ConA \\
\hline CAV-2-ROP18 (I) & $914.26 \pm 36.56^{a}$ & $431.07 \pm 28.94^{a}$ & $197.29 \pm 29.98^{a}$ & $44.37 \pm 38.54^{a}$ & $4.87 \pm 0.65^{a}$ & $2.93 \pm 0.43^{\mathrm{a}}$ \\
\hline CAV-2 (II) & $44.28 \pm 9.37^{b}$ & $47.23 \pm 7.59^{b}$ & $52.65 \pm 9.24^{b}$ & $38.49 \pm 5.48^{\mathrm{a}}$ & $0.23 \pm 0.06^{b}$ & $3.07 \pm 0.19^{a}$ \\
\hline PBS (III) & $46.13 \pm 10.27^{b}$ & $52.60 \pm 11.97^{b}$ & $54.87 \pm 9.45^{b}$ & $41.36 \pm 5.23^{\mathrm{a}}$ & $0.26 \pm 0.10^{b}$ & $2.81 \pm 0.32^{\mathrm{a}}$ \\
\hline Blank Control (IV) & $42.98 \pm 6.76^{\mathrm{b}}$ & $51.45 \pm 3.88^{b}$ & $53.38 \pm 5.97^{\mathrm{b}}$ & $40.63 \pm 6.74^{\mathrm{a}}$ & $0.27 \pm 0.07^{b}$ & $2.84 \pm 0.26^{\mathrm{a}}$ \\
\hline
\end{tabular}

*Data are reported as mean \pm SD.

"Splenocytes from mice were collected 8-weeks after the immunization.

Values for IL-10 and IFN- $\gamma$ are for $72 \mathrm{~h}$, values for IL-2 and IL- 4 are for $24 \mathrm{~h}$.

Within each column, groups with different superscripts are different $(P<0.05)$. 


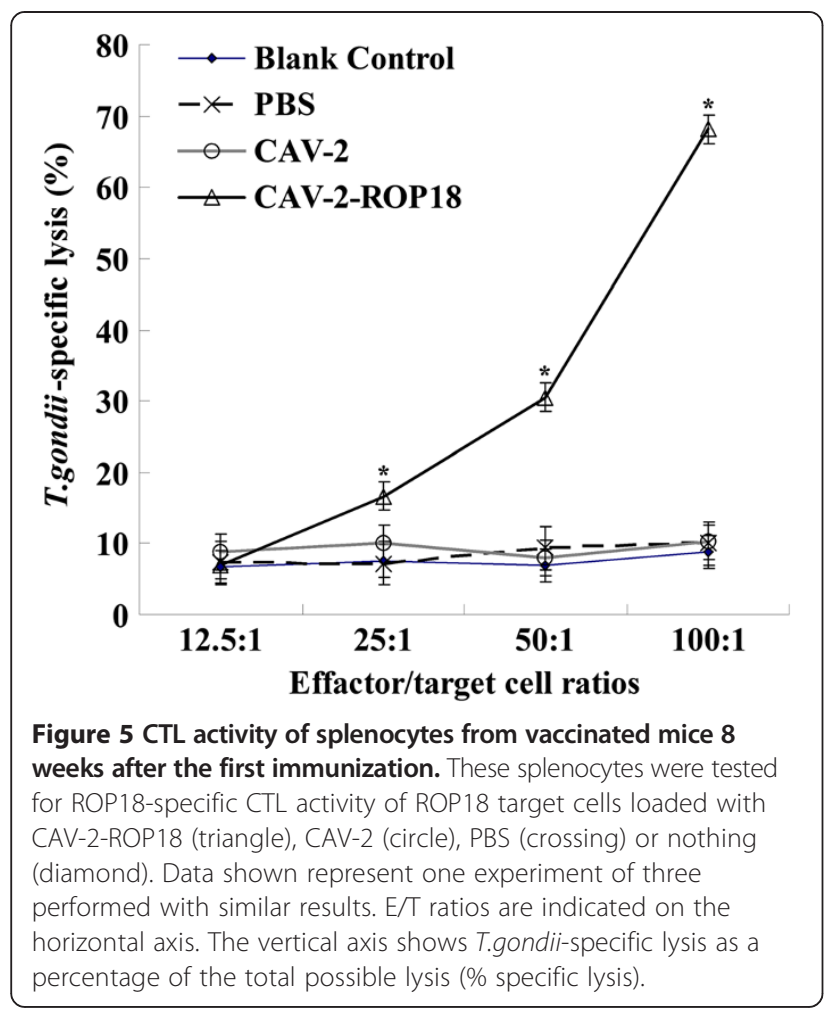

found that the mice immunized with CAV-2-ROP18 significantly increased the antigen-specific IgG compared with the mice immunized with CAV-2 or PBS. This result indicated that adenovirus vector is highly efficient for gene transfer and expression.

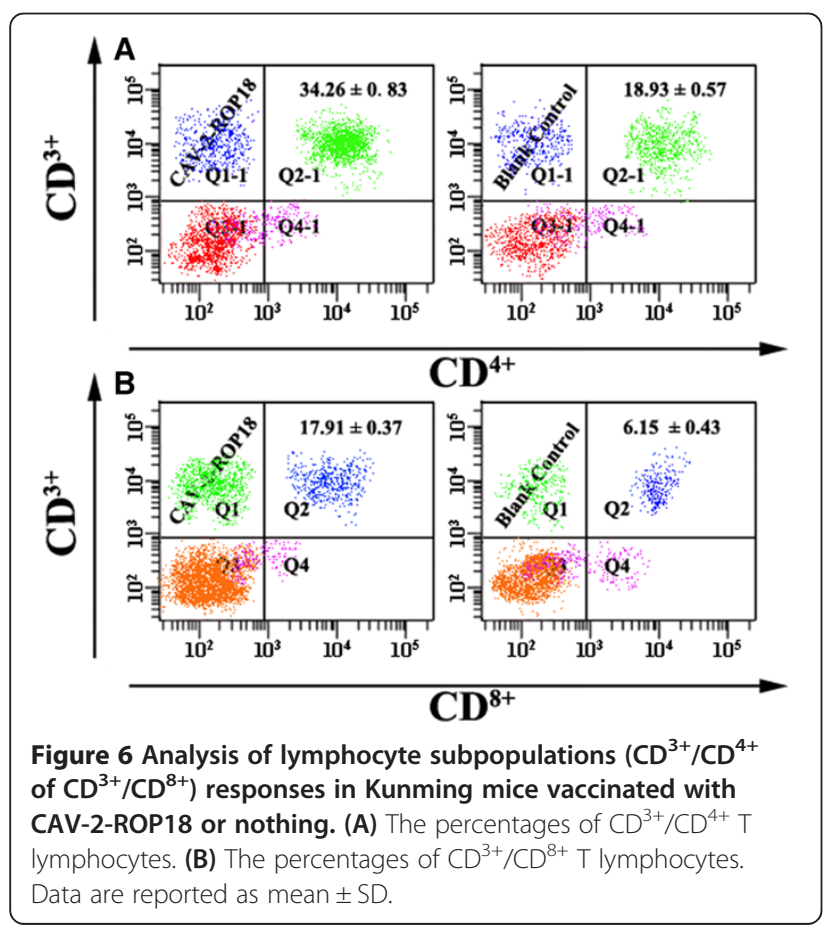

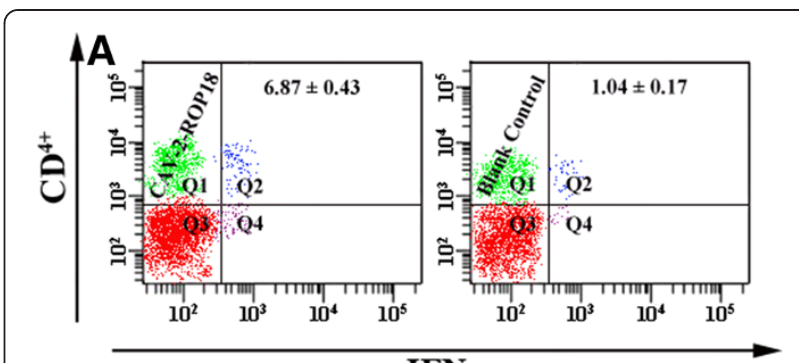

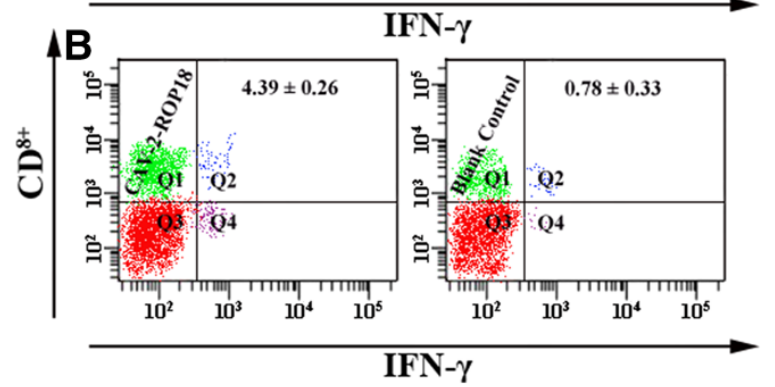

Figure 7 The expression of IFN- $\gamma$ on $\mathrm{CD}^{4+}$ and $\mathrm{CD}^{8+} \mathrm{T}$ cells using flow cytometry analysis. The percentages of IFN- - -producting cells inside $C^{4+} T$ cell gate $(\mathbf{A})$ and IFN- $\gamma$-producting cells inside $C^{8+} T$ cell gate $\mathbf{( B )}$ in mice spleen cells. Data are reported as mean \pm SD.

Previous studies demonstrated that DNA vaccine expressing T. gondii antigens could elicit both humoral and cell-mediated immunity and prolong the survival time in mice $[4,13,15,34-37]$. However, no protection was observed in mice, regardless of DNA vaccine or recombinant virus vaccine $[4,13,15,34-37]$. In our study, we improved the survival rate, which is up to $40 \%$ protection in mice immunized with CAV-2-ROP18 after challenge with lethal RH strain of $T$. gondii. PRU strain (genotype II) of $T$. gondii was used in our research in order to scientifically evaluate immunoprotection while using many more mice in this test. We also obtained a $57.3 \%$ reduction in brain cysts after immunization of mice with CAV-2-ROP18. Furthermore, the cross-protective immunity has been demonstrated, despite the existing $7.5 \%$ sequence variation between type I (RH strain) and type II (PRU strain).

CAV-2-ROP18 could elicit antigen-specific $\mathrm{CD}^{+}{ }^{+} \mathrm{T}$ cells and $\mathrm{CD}^{+} \mathrm{T}$ cells responses in mice. However, their major advantage at the immunological level has been their capacity to induce antigen-specific $\mathrm{CD}^{+} \mathrm{T}$ cell responses, including CTLs, which is a major mechanism of protection against intracellular pathogens. Some studies have shown that CTLs are involved in cyst control during $T$. gondii infection in a mechanism mediated by perforin [38]. Meanwhile, it is very important that $\mathrm{CD}^{+} \mathrm{T}$ cells, particularly in synergy with $\mathrm{CD} 4^{+} \mathrm{T}$ cells, contributed to the control of the spreading and development of T. gondii infection $[39,40]$. In agreement with this efficacy, we observed the increase of the percentage of $\mathrm{T} \mathrm{CD} 8^{+}$and $\mathrm{T} \mathrm{CD} 4^{+}$cells in mice immunized with CAV-2-ROP18, which also suggested the activation of $\mathrm{CD} 4^{+}$and $\mathrm{CD} 8^{+} \mathrm{T}$ 

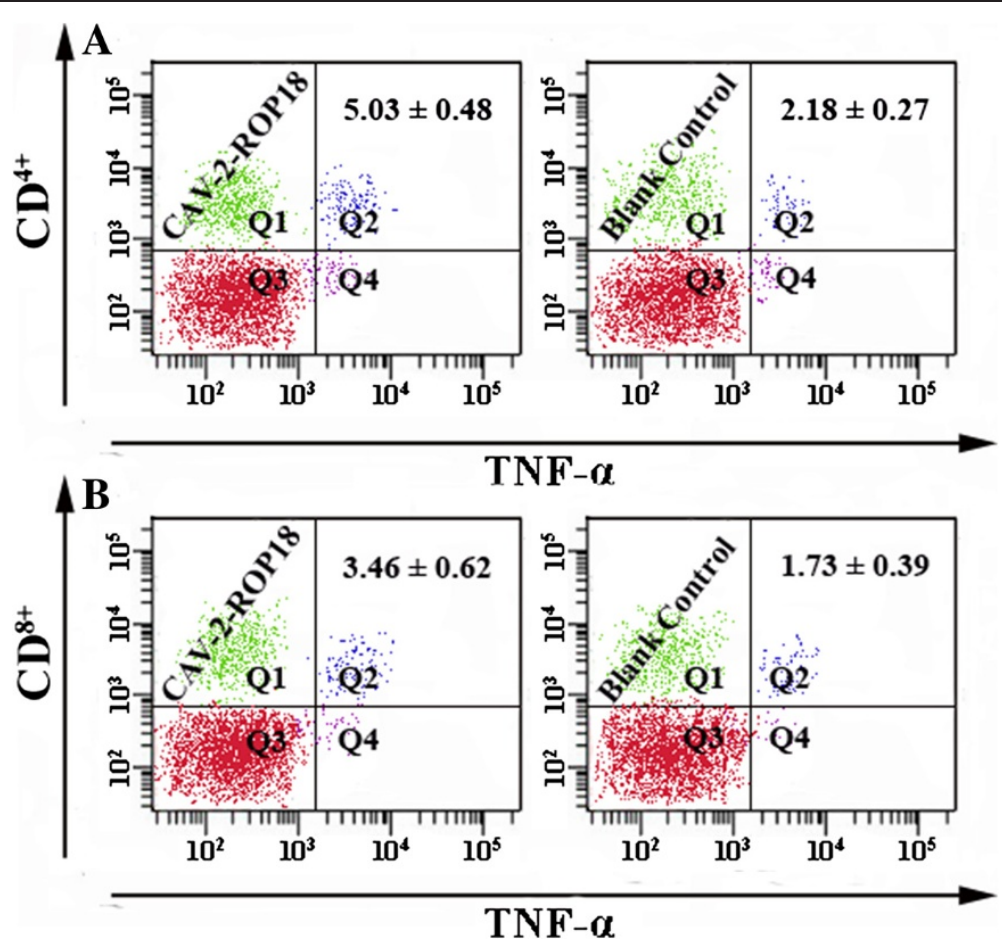

Figure 8 The expression of TNF- $a$ on $\mathrm{CD}^{4+}$ and $\mathrm{CD}^{8+} \mathrm{T}$ cells using flow cytometry analysis. A, percentages of TNF-a-producting cells inside $C D^{4+} \mathrm{T}$ cell gate. $\mathbf{B}$, percentages of TNF-a-producting cells inside $\mathrm{CD}^{8+} \mathrm{T}$ cell gate. Data are reported as mean $\pm \mathrm{SD}$.

cells, and thus may be in synergy to contribute to cytotoxic activity against $T$. gondii. Additionally, the present study showed that $\mathrm{CD}^{+}$and $\mathrm{CD}^{+} \mathrm{T}$ cells were upregulated after the administration of CAV-2-ROP18, at least in terms of frequency of both type cells producing IFN- $\gamma$ of TNF- $\alpha$, which was observed in cytotoxicity assay

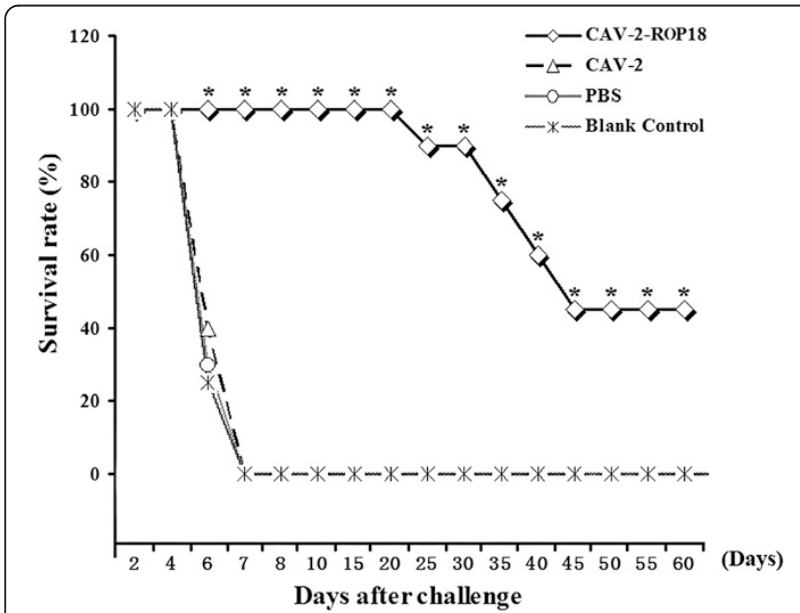

Figure 9 Survival rate of mice immunized with CAV-2-ROP18 $(\diamond)$, CAV-2 ( $\Delta)$, PBS $(* *)$ and nothing $(*)$, then challenged with $1 \times 10^{3}$ tachyzoites. Each group had 20 mice. Statistically significant differences $(P<0.05)$ are indicated by an asterisk $\left(^{*}\right)$, which of CAV-2-ROP18 are listed differently compared to the other other control groups. in vitro. The CTL activity in the group immunized with CAV-2-ROP18 was significantly higher than that of the group injected with pVAX-ROP18 alone, as previously described (T. gondii-specific lysis is $68 \%$ vs $47 \%$ ) [13].

\section{Conclusions}

In summary, our work presents the successful use of recombinant virus CAV-2-ROP18 in vaccination protocols to protect against intraperitoneal and intragastrical challenge with virulent RH strain or attenuated PRU strain of T. gondii. This system was shown to be extremely efficient in eliciting humoral and cellular immune responses. Therefore, the CAV-2-ROP18 may be potentially useful in the development of an effective vaccine against $T$. gondii infection in the future.

Table 3 Mean cyst burden per mouse brain 30 days after injection with 5 cysts of PRU strain by intragastrical route

\begin{tabular}{lll}
\hline Group $(\mathbf{n}=\mathbf{5})$ & No. of brain cysts $^{*}$ & Reduction $^{\mathbf{*}} \mathbf{0}^{\#}$ \\
\hline CAV-2-ROP18 (I) & $8000 \pm 1414^{\mathrm{a}}$ & 57.3 \\
CAV-2 (II) & $17480 \pm 1584^{\mathrm{b}}$ & 6.6 \\
PBS (III) & $18080 \pm 642^{\mathrm{b}}$ & 3.4 \\
Blank Control (IV) & $18720 \pm 955^{\mathrm{b}}$ & -
\end{tabular}

*Data are reported as mean \pm SD.

${ }^{a, b}$ The same letter indicates no difference $(P>0.05)$, whereas different letters indicate a significant difference $(P<0.05)$.

"From the values for the blank control. 


\section{Additional files}

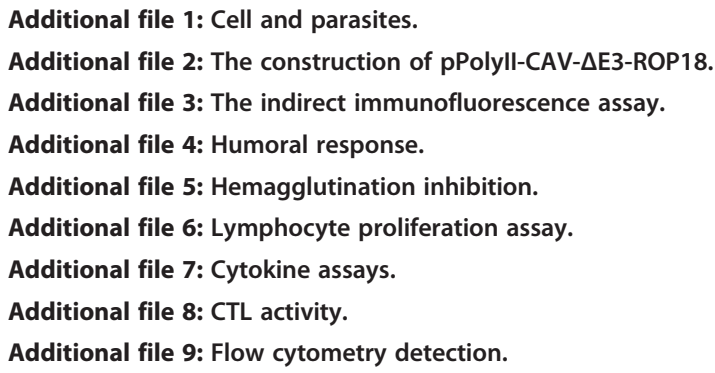

\section{Competing interests}

The authors declare that they have no competing interests.

\section{Authors' contributions}

ZGY, SJL, XZL and XHW conceived and designed the study. JAH critically revised the manuscript. $X Z L, X H W, L J X, Y B W, L Q T$ and $L T L$ performed the experiments. XZL and XHW analyzed the data and drafted the manuscript. All authors read and approved the final manuscript.

\section{Acknowledgements}

This study was supported, in part, by grants from the National Program for High Technology Research (2011AA10A215), the Project of Science and Technology New Star of Zhu Jiang (2011J2200100), the FOK YING TUNG Education Foundation (141029), the Special Fund for Agro-scientific Research in the Public Interest (Grant No. 201303042), Guangdong Provincial Key Laboratory of Prevention and Control for Severe Clinical Animal Diseases (2013A061401013), the Scientific and Technological Planning Project of Guangdong Province (Grant No. 2010B020307006) and the National Natural Science Foundation of China (31201918 and 30901067). We are grateful Prof. Hernandez in revision of the MS.

\section{Author details}

${ }^{1}$ College of Veterinary Medicine, South China Agricultural University, Guangzhou, Guangdong Province 510642, PR China. Guangdong Provincial Key Laboratory of Prevention and Control for Severe Clinical Animal Diseases, Guangzhou, Guangdong Province 510642, PR China. ${ }^{3}$ Institute of Animal Health, Guangdong Academy of Agricultural Sciences, Guangzhou, Guangdong Province 510642, PR China. ${ }^{4}$ Department of Large Animal Clinical Sciences, College of Veterinary Medicine, University of Florida, Gainesville, Florida, USA.

Received: 2 June 2014 Accepted: 9 February 2015

\section{Published online: 04 March 2015}

\section{References}

1. Denkers EY, Gazzinelli RT. Regulation and function of T-cell-mediated immunity during Toxoplasma gondii infection. Clin Microbiol Rev. 1988;11:569-88.

2. Sabin AB. Toxoplasmic encephalitis in children. J Am Med Assoc. 1941;116:801-7.

3. Pinkerton $\mathrm{H}$, Henderson RG. Adult toxoplasmosis: a previously unrecognized disease entity simulating the typhus-spotted fever group. J Am Med Assoc. 1941;116:807-14.

4. Yuan ZG, Ren D, Zhou DH, Zhang XX, Petersen E, Li XZ, et al. Evaluation of protective effect of pVAX-TgMIC13 plasmid against acute and chronic Toxoplasma gondii infection in a murine model. Vaccine. 2013;31:3135-9.

5. Tenter AM, Heckeroth AR, Weiss LM. Toxoplasma gondii: from animals to humans. Int J Parasitol. 2000;30:1217-58.

6. Vercruysse J, Knox DP, Schetters TP, Willadsen P. Veterinary parasitic vaccines: pitfalls and future directions. Trends Parasitol. 2004;20:488-92.

7. Kur J, Holec-Gasior L, Hiszczyńska-Sawicka E. Current status of toxoplasmosis vaccine development. Expert Rev Vaccines. 2009;8:791-808.

8. Taylor S, Barragan A, Su C, Fux B, Fentress SJ, Tang K, et al. A secreted serine-threonine kinase determines virulence in the eukaryotic pathogen Toxoplasma gondii. Science. 2006;314:1776-80.
9. Saeij JP, Boyle JP, Coller S, Taylor S, Sibley LD, Brooke-Powell ET, et al. Polymorphic secreted kinases are key virulence factors in toxoplasmosis. Science. 2006;314:1780-3.

10. Lim D, Gold DA, Julien L, Rosowski EE, Niedelman W, Yaffe MB, et al. Structure of the Toxoplasma gondii ROP18 Kinase Domain Reveals a Second Ligand Binding Pocket Required for Acute Virulence. J Biol Chem. 2013;288:34968-80.

11. Dudek T, Knipe DM. Replication-defective viruses as vaccines and vaccine vectors. Virology. 2006;344:230-9.

12. Yang TC, Millar JB, Grinshtein N, Bassett J, Finn J, Bramson JL. T-cell immunity generated by recombinant adenovirus vaccines. Expert Rev Vaccines. 2007;6:347-56.

13. Yuan ZG, Zhang XX, Lin RQ, Petersen $E$, He S, Yu M, et al. Protective effect against toxoplasmosis in mice induced by DNA immunization with gene encoding Toxoplasma gondii ROP18. Vaccine. 2011;29:6614-9.

14. Yin Z, Liu JH. Animal virology. Beijing: Science Press; 1997 [in Chinese].

15. Yuan ZG, Zhang XX, He XH, Petersen E, Zhou DH, He Y, et al. Protective immunity induced by Toxoplasma gondii rhoptry protein 16 against toxoplasmosis in mice. Clin Vaccine Immunol. 2011;18:119-24.

16. Bounous DI, Campagnoli RP, Brown J. Comparison of MTT colorimetric assay and tritiated thymidine uptake for lymphocyte proliferation assays using chicken splenocytes. Avian Dis. 1992;36:1022-7.

17. Appledorn DM, Patial S, Godbehere S, Parameswaran N, Amalfitano A. TRIF, and TRIF-interacting TLRs differentially modulate several adenovirus vector-induced immune responses. J Innate Immun. 2009;1:376-88.

18. Appledorn DM, Patial S, McBride A, Godbehere S, Van Rooijen N, Parameswaran N, et al. Adenovirus vector-induced innate inflammatory mediators, MAPK signaling, as well as adaptive immune responses are dependent upon both TLR2 and TLR9 in vivo. J Immunol. 2008;181:2134-44.

19. Muruve DA, Petrilli V, Zaiss AK, White LR, Clark SA, Ross PJ, et al. The inflammasome recognizes cytosolic microbial and host DNA and triggers an innate immune response. Nature. 2008;452:103-7.

20. Zakhartchouk AN, Reddy PS, Baxi M, Baca-Estrada ME, Mehtali M, Babiuk LA, et al. Construction and characterization of E3-deleted bovine adenovirus type 3 expressing full length and truncated form of bovine herpesvirus type 1 glycoprotein gD. Virology. 1998;250:220-9.

21. Morrison MD, Reid D, Onions D, Spibey N, Nicolson L. Generation of E3-deleted canine adenoviruses expressing canine parvovirus capsid by homologous recombination in bacteria. Virology. 2002;293:26-30.

22. Wang SL, Chi CY, Kuo PH, Tsai HP, Wang SM, Liu CC, et al. High-incidence of human adenoviral co-infections in taiwan. PLoS ONE. 2013;8:e75208.

23. Zhang S, Huang W, Zhou X, Zhao Q, Wang Q, Jia B. Seroprevalence of neutralizing antibodies to human adenoviruses type- 5 and type- 26 and chimpanzee adenovirus type-68 in healthy Chinese adults. J Med Virol. 2013;85:1077-84.

24. Fan QS, Xia XZ, Gao YW, Huang G. Attenuation SY strain of CAV-2 strain. Chin J Vet. 1982;35:7-9 (in Chinese).

25. Fang Q, Zhang S, Wang S, Liu Y, Zhao J, Mi L, et al. Neutralizing antibody against canine adenovirus in dogs. Chinese Journal of Zoonoses. 2014;30:155-7 (in Chinese).

26. Mosmann TR, Coffman RL. TH1 and TH2 cells: different patterns of lymphokine secretion lead to different functional properties. Annu Rev Immunol. 1989;7:145-73.

27. Garcia JL. Vaccination concepts against Toxoplasma gondii. Expert Rev Vaccines. 2009;8:215-25.

28. Gigley JP, Fox BA, Bzik DJ. Cell-mediated immunity to Toxoplasma gondii develops primarily by local Th1 host immune responses in the absence of parasite replication. J Immunol. 2009;182:1069-78.

29. Matowicka-Karna J, Dymicka-Piekarska V, Kemona H. Does Toxoplasma gondii infection affect the levels of IgE and cytokines (IL-5, IL-6, IL-10, IL-12, and TNF-alpha)? Clin Dev Immunol. 2009;2009:374696.

30. Wilson DC, Matthews S, Yap GS. IL-12 signaling drives CD8 ${ }^{+} T$ cell IFN-gamma production and differentiation of KLRG+ effector subpopulations during Toxoplasma gondii infection. J Immunol. 2008;180:5935-45.

31. Dupont CD, Christian DA, Hunter CA. Immune response and immunopathology during toxoplasmosis. Semin Immunopathol. 2012;34:793-813.

32. Wurtz O, Bajenoff M, Guerder S. IL-4-mediated inhibition of IFN-gamma production by $\mathrm{CD}^{+} \mathrm{T}$ cells proceeds by several developmentally regulated mechanisms. Int Immunol. 2004;16:501-8.

33. Sayles PC, Gibson GW, Johnson LL. B cells are essential for vaccinationinduced resistance to virulent Toxoplasma gondii. Infect Immun. 2000;68:1026-33. 
34. Yan $H K$, Yuan $Z G$, Song $H Q$, Petersen E, Zhou Y, Ren D, et al. Vaccination with a DNA vaccine coding for perforin-like protein 1 and MIC6 induces significant protective immunity against Toxoplasma gondii. Clin Vaccine Immunol. 2012;19:684-9.

35. Wang PY, Yuan ZG, Petersen E, Li J, Zhang XX, Li XZ, et al. Protective efficacy of a Toxoplasma gondii rhoptry protein 13 plasmid DNA vaccine in mice. Clin Vaccine Immunol. 2012;19:1916-20.

36. Chen J, Huang SY, Zhou DH, Li ZY, Petersen E, Song HQ, et al. DNA immunization with eukaryotic initiation factor-2a of Toxoplasma gondil induces protective immunity against acute and chronic toxoplasmosis in mice. Vaccine. 2013;31:6225-31

37. Zhang NZ, Huang SY, Zhou DH, Chen J, Xu Y, Tian WP, et al. Protective immunity against Toxoplasma gondii induced by DNA immunization with the gene encoding a novel vaccine candidate: calcium-dependent protein kinase 3. BMC Infect Dis. 2013;13:512.

38. Suzuki Y, Wang $X$, Jortner BS, Payne L, Ni Y, Michie SA, et al. Removal of Toxoplasma gondii cysts from the brain by perforin-mediated activity of CD8 ${ }^{+}$T cells. Am J Pathol. 2010;176:1607-13.

39. Jongert E, Lemiere A, Van Ginderachter J, De Craeye S, Huygen K, D'Souza S. Functional characterization of in vivo effector CD4(+) and CD8(+) T cell responses in acute Toxoplasmosis: an interplay of IFN-gamma and cytolytic T cells. Vaccine. 2010;28:2556-64.

40. Casciotti L, Ely KH, Williams ME, Khan IA. CD8(+)-T-cell immunity against Toxoplasma gondii can be induced but not maintained in mice lacking conventional CD4(+) T cells. Infect Immun. 2002;70:434-43.

\section{Submit your next manuscript to BioMed Central and take full advantage of:}

- Convenient online submission

- Thorough peer review

- No space constraints or color figure charges

- Immediate publication on acceptance

- Inclusion in PubMed, CAS, Scopus and Google Scholar

- Research which is freely available for redistribution 